\title{
PENGALAMAN KELUARGA MENGHADAPI TRAUMA PASCA BENCANA ALAM DI KAMPUNG LEBO KECAMATAN MANGANITU
}

\author{
FAMILY EXPERIENCE to FACE TRAUMA AFTER NATURAL DISASTER \\ IN LEBO VILLAGE MANGANITU DISTRICT
}

\author{
Yenny Budiman Makahaghi, Conny Juliana Surudani \\ Program Studi Keperawatan, Politeknik Negeri Nusa Utara \\ Email: ymakahaghi@gmail.com
}

\begin{abstract}
Abstrak: Bencana tidak bisa lepas dari siapapun jika sudah kehendak sang kuasa pasti akan terjadi, dan keluarga yang mengalami dampak dari bencana alam ini harus bisa menerima setiap kenyataan hidup yang sudah terjadi. Bencana alam yang dialami membuat keluarga kehilangan rumah, harta benda bahkan anggota keluarga yang sangat dikasihi. Pengalaman yang sangat menyakitkan ini adalah bagian dari kehidupan yang harus dijalani pasca bencana alam. Tujuan dari penelitian ini adalah untuk menguraikan pengalaman keluarga menghadapi bencana alam di kampung Lebo. Metode: penelitian ini menggunakan metode penelitian kualitatif fenomenologi dengan teknik wawancara mendalam kepada 6 keluarga yang terdampak bencana alam di Kampung Lebo Kecamatan Manganitu. Analisis data yang digunakan mengacu pada tujuh langkah teknik analisis data collaizi. Hasil: Penelitian ini menunjukkan keluarga merasakan dampak trauma pasca bencana alam sehingga ditemukan tujuh tema besar yaitu 1) Tanda awal bencana, 2) Respon terhadap banjir, 3) Beban psikologi 4) Jenis dukungan, 5) Beban ekonomi, 6) Makna setelah terjadi bencana, 7) Harapan untuk Lebo. Tujuh tema tersebut saling berhubungan satu dengan yang lain dan merupakan pengalaman hidup partisipan menghadapi pasca trauma bencana alam. Kesimpulan: Akibat dari kejadian ini menyebabkan keluarga mengalami beban psikologi karena kehilangan barang berharga. Meskipun sulit menerima kenyataan harus kehilangan yang orang yang dikasihi serta benda berharga tetapi dukungan yang selalu datang dari berbagai pihak sehingga keluarga mengurangi beban yang dialami. Dengan kejadian ini keluarga mengalami perubahan ekonomi dalam memenuhi kebutuhan sehari-hari. Melalui kejadian ini keluarga menyadari bahwa ini kehendak sang pencipta sehingga harapan kedepan bencana alam ini tidak akan terjadi lagi di kampung.
\end{abstract}

Kata kunci: Keluarga, Bencana alam, Manganitu Sangihe

\begin{abstract}
Disasters cannot be separated from anyone if the power has the will of it, it will definitely happen, and families who experience the impact of this natural disaster must be able to accept it. The natural disasters experienced have made families lose their homes, property and even loved family members. This painful experience is a part of life that must be lived after a natural disaster. The purpose of this study is to describe the experiences of families facing natural disasters in Lebo village. Methods: This study used a phenomenological qualitative research method with in-depth interviews with 6 (six) families affected by natural disasters in Lebo Village, Manganitu District. The data analysis used refers to the seven steps of the Collaizi data analysis technique. Results: Those study showed that families feel the impact of trauma after natural disasters so that seven major themes were found, 1) Early signs of disaster, 2) Response to flood, 3) Psychological burden 4) Types of support, 5) Economic burden, 6) Meaning after a disaster, 7) Hope for Lebo. The seven themes were interconnected with one another and represent the life experiences of the participant in dealing with natural disasters. Conclusion: The consequences of those incident caused the family to experience a psychological burden due to the loss of valuables. Even though it was difficult to accept the fact that you were lose loved ones and valuable objects, support always come from all people so that the family could reduces the burden experienced. With this incident the family experienced economic changes in meeting their daily needs. Through those incident the family realized those was the creator's will so that in the future this natural disaster would not happen again in the Lebo village.
\end{abstract}

Keywords: Family, Natural disaster, Manganitu Sangihe 


\section{PENDAHULUAN}

Bencana tidak bisa lepas dari siapapun jika sudah kehendak sang kuasa pasti akan terjadi, dan keluarga yang mengalami dampak dari bencana alam ini harus bisa menerima setiap kenyataan hidup yang sudah terjadi. Menurut warga setempat bencana alam ini sudah pernah terjadi sebelumnya yaitu pada tahun 2000 dimana banjir dan longsor juga merusak perkampungan mereka dan kembali terjadi pada tahun 2008 empat rumah warga hilang akibat banjir. Bencana alam yang dialami pada tahun 2020 ini, merupakan kejadian yang paling parah dari sebelumnya dimana banyak warga masyarakat harus kehilangan rumah, harta benda bahkan anggota keluarga yang sangat dikasihi. Pengalaman yang sangat menyakitkan ini adalah bagian dari kehidupan yang harus dijalani pasca bencana alam. Kejadian banjir bandang yang terjadi di Kecamatan Manganitu pada bulan Januari 2020 mengakibatkan kerugian harta benda serta rusaknya infrastruktur daerah dan adanya korban jiwa karena tertimbun sebanyak 5 orang.

Menurut Kementrian Kesehatan tahun 2012, bencana alam di Indonesia terjadi sebanyak 211 kali dengan 53,3\% merupakan bencana hidrometeorologi $(34,1 \%)$ diataranya adalah bencana banjir. Pada tahun 2003-2010, terdapat 5.186 kejadian bencana alam akibat banjir, 45,5\% dari total bencana alam yang terjadi. Data Indeks Rawan Bencana tahun 2011 menyebutkan bahwa Provinsi Jawa Timur berada pada urutan ketiga wilayah rawan bencana yang ada di Indonesia (Kemenkes, 2012)

Banjir bandang merupakan suatu keadaan atau kejadian melalui aliran air yang deras dan pekat disertai jatuhnya bongkahan batu-batuan, tanah dan batang-batang kayu dari arah hulu sungai. Banjir bisa terjadi disebabkan oleh faktor hidrologi yaitu intentitas air hujan yang tinggi, geologis antara lain longsor, faktor klimatologis, serta pembendungan alamiah di daerah hulu. Kenaikan air debit secara tiba-tiba dan cepat dapat menyebabkan banjir sehingga menyebabkan bencana alam. (Purwastuty, 2019). Akibat dari banjir dapat menimbulkan kerugian bagi kehidupan masyarakat yang terdampak dengan banjir tersebut sehingga mempengaruhi derajat kesehatan fisik maupun non-fisik seperti trauma yang dirasakan saat peristiwa yang pernah dialami kembali lagi terjadi. Post Traumatic Stress Disorder merupakan salah satu dampak psikologis yang sering dialami oleh korban bencana alam (Nurcahyani, 2016).

Beberapa masalah yang sering terjadi berkaitan dengan kesehatan akibat bencana alam yaitu bersifat fisik, maupun psikologis (stres) atau campuran keduanya. Dampak psikologis akibat bencana alam yang paling khas yaitu respon stres pasca bencana alam yang dirasakan langsung baik itu orang dewasa maupun anak-anak. Penyebab lain yang berperan terhadap dampak psikologis adalah perasaan kehilangan kontrol atas kehidupan seseorang dan perasaan takut bahwa bencana itu akan datang lagi. Gejala yang umum terjadi pada korban bencana seperti kelelahan, konsentrasi terganggu, gangguan pemusatan perhatian, kebingungan, kecemasan, depresi, rasa duka, penyalah gunaan zat, gangguan tidur, perubahan pola makan, dan dapat berlajut ke Post Traumatic Stress Disorder (PTSD), (Santiago, 2013). Menurut Pranoto (2011) Bencana alam yang terjadi dapat berdampak pada aspek kehidupan ekonomi keluarga. Akibat dari kejadian alam banyak kerugian yang dialami oleh masyarakat terkena dampak dan kerugian ekonomi ini dapat mempengaruhi hilangnya beberapa faktor produktif yang menggerakkan kehidupan manusia, termaksud perpindahan penduduk ke luar daerah yang rawan terhadap bencana.

Kampung Lebo memiliki kurang lebih 500 kepala keluarga dengan latar belakang pekerjaan sebagian besar adalah petani. Pada bulan Januari 2020 Kampung Lebo mengalami bencana alam banjir dan longsor yang sangat dasyat sehingga menyebabkan 
warga masyarakat kehilangan rumah, harta benda bahkan anggota keluarga yang dikasihi. Survey awal yang dilakukan pada tanggal 5-7 Juli 2020 enam keluarga yang mengalami dampak pasca bencana yang dialami adalah kehilangan mata pencaharian dan hasil perkebunan. Selain itu keluarga juga mengungkapkan perasaan takut dan cemas ketika hujan turun. Awal mulanya bencana itu terjadi disebabkan oleh derasnya hujan. Tujuan penelitian ini mengeksplorasikan pengalaman keluarga menghadapi trauma pasca bencana alam di kampung Lebo Kecamatan Manganitu.

\section{METODE PENELITIAN}

Penelitian ini menggunakan desain kualitatif mengeksplorasi informasi yang mendalam tentang pengalaman keluarga menghadapi trauma pasca bencana alam. Penelitian ini dilaksanakan pada bulan September 2020 di kampung Lebo. Partisipan dalam penelitian ini berjumlah enam keluarga, Pengambilan sampling menggunakan teknik sampling secara Purposive Sampling, dengan inklusi: mampu berkomunikasi dengan baik, tidak sedang sakit fisik berat, keluarga yang terkena dampak bencana alam, tinggal dikampung Lebo, bersedia menjadi partisipan penelitian. Pengumpulan data dilakukan dengan wawancara mendalam dimana instrumen penelitian ini adalah peneliti sendiri dalam mengembangkan pertanyaan dalam bentuk wawancara menggunakan pedoman wawancara, catatan lapangan dan recorder karena informan tidak bersedia menggunakan video kamera. Proses analisis data dilakukan dengan menggunakan Metode Collaizi yang terdiri dari tujuh tahapan. Validitas data penelitian, peneliti melakukan Triangulasi yaitu triangulasi metode dengan wawancara dan observasi serta triangulasi antar anggota peneliti untuk menghindari subjektifitas peneliti. Selain itu peneliti melakukan member cheking yaitu dengan validasi data hasil wawancara partisipan.
Partisipan adalah salah satu anggota keluarga yang terdampak bencana alam. Partisipan yang memberikan informasi dalam penelitian ini memiliki jenis kelamin sama banyak baik laki-laki maupun perempuan dengan latar belakang pendidikan terbanyak yaitu SMA, usia tertua 84 tahun dan termuda 36 tahun. Pekerjaan terbanyak sebagai ibu rumah tangga dan semua partisipan berasal dari suku Sangihe.

Tabel 1. Karakteristik Informan

\begin{tabular}{|c|c|c|c|c|c|}
\hline Kode & $\mathrm{J} / \mathrm{K}$ & Usia & Suku & $\begin{array}{c}\text { Pendidkan } \\
\text { terakhir }\end{array}$ & Pekerjaan \\
\hline $\mathrm{P} 1$ & $\mathrm{~L}$ & 58 tahun & Sangihe & $\mathrm{D} 2$ & Nelayan \\
\hline $\mathrm{P} 2$ & $\mathrm{P}$ & 36 tahun & Sangihe & SMA & $\begin{array}{l}\text { Ibu rumah } \\
\text { tangga }\end{array}$ \\
\hline P3 & $\mathrm{P}$ & 39 tahun & Sangihe & SMA & $\begin{array}{l}\text { Ibu rumah } \\
\text { tangga }\end{array}$ \\
\hline $\mathrm{P} 4$ & $\mathrm{~L}$ & 84 tahun & Sangihe & $\mathrm{SD}$ & Petani \\
\hline P5 & $\mathrm{P}$ & 49 tahun & Sangihe & SMA & $\begin{array}{l}\text { Ibu rumah } \\
\text { tangga }\end{array}$ \\
\hline P6 & $\mathrm{L}$ & 46 tahun & Sangihe & SMA & Nelayan \\
\hline
\end{tabular}

\section{HASIL DAN PEMBAHASAN}

\section{Tema 1: Tanda Awal Bencana}

Keadaan musim di Kabupaten Kepulauan Sangihe pada awal tahun 2020 tidaklah menentu terkadang hujan terkadang panas.Bencana alam yang terjadi di Kampung Lebo Kecamatan Manganitu sangat dirasakan oleh masyarakat yang berdomisili dikampung tersebut. Bencana alam yang terjadi awal mulainya ditandai oleh hujan deras yang tak kunjung berhenti sehingga air sungai meluap dan menyebabkan banjir. Tanda-tanda bencana alam diungkapkan oleh P1, P2, P3, P4, P5 dan P6 bahwa bencana alam sudah ketiga kalinya dan sama dengan sebelumnya hujan deras mengguyur kampung Lebo tetapi yang paling parah bencana terjadi pada bulan Januari 2020. Menurut Ridha (2017) banjir terjadi biasanya karena sungai atau saluran tidak mampu mengalirkan air hujan yang mengalir di atas permukaan sehingga aliran permukaan dari semua arah dan dari semua tempat

$$
\text { menuju saluranMenurut Tondobala }
$$
mengungkapkan bahwa Tanah longsor terjadi jika dipenuhi 3 keadaan yaitu lereng cukup curang, dan di 
bawah permukaan tanah terdapat kedap air yang cukup banyak. Air hujan yang jatuh di atas permukaan tanah kemudian menjenuhi tanah sehingga hal ini sangat menentukan kestabilan lereng, dengan menurunnya ketahanan geser tanah yang jauh lebih besar daripada penurunan tekanan geser tanah, faktor keamanan lereng menurun tajam, menyebabkan lereng rawan longsor. Tanda dari awal bencana alam yang dialami oleh partisipan adalah durasi hujan yang lama sehingga menyebabkan air meluap dari sungai dan terjadi banjir dan longsor.Dengan kejadian ini partisipan dan keluarga harus mengamankan diri agar terhindar dari bencana alam.

\section{Tema 2: Respon Terhadap Banjir}

Respon partisipan yang ditemukan dalam penelitian ini yaitu berusaha menghindar dari bencana yang akan datang dimana partisipan mengajak anggota keluarga yang lain untuk lari ataumengamakan diri saat hujan dan tanda-tanda bencana alam itu mulai nampak didepan mata. Menurut Ridha (2017) Sikap seseorang dalam menyikapi bencana alam tergantung dari pengetahuan individu dalam merespon bencana alam yang akan terjadi sehingga mempengaruhi seseorang untuk bertindak. Respon keluarga saat melihat bencana itu mulai datang dengan berteriak untuk memberitahukan kepada warga masyarakat yang lain bahwa bencana alam akan terjadi sehingga warga masyarakat yang beresiko terkena banjir dan longsor bisa segera mencari tempat yang aman dan terhindar dari bencana tersebut. Dengan kejadian ini mereka harus kehilangan rumah, harta benda bahkan anggota keluarga yang dikasihi. Perasaan takut, cemas dengan alam juga kecewa menghampiri ketika bencana yang tidak diharapkan terjadi didalam kehidupan mereka. Menurut Anika (2019) dalam penelitiannya mengungkapkan gejala yang mencerminkan stres pasca-trauma, gangguan kecemasan dan depresi. Terdapat juga berbagai perilaku berisiko dan keluhan somatik sehingga dapat meningkatnya tingkat bunuh diri di kalangan anak muda. Keadaan ini membuat partisipan dan keluarga harus mengambil langkah awal yaitu menghindari dampak dari hujan yang tak kunjung berhenti. Sehingga respon warga saat hujan deras adalah melarikan diri ketempat yang aman dan meninggalkan tempat tinggal mereka yang beresiko terjadi bencana alam. Bencana bisa terjadi kapan saja dan respon terhadap bencana tergantung dari pengetahuan seseorang dalam menyikapi atau menghindari bencana yang akan terjadi (Findayani, 2015)

\section{Tema 3: Beban Psikologi}

Beban psikologi dalam menghadapi bencana alam sangat dirasakan oleh keluarga saat menghadapi bencana alam, perasaan kecewa dan sedih karena kehilangan anggota keluarga dan harta benda diungkapkan oleh P1, P2, P3, P4, P5 \& P6. Menurut Elita, dkk (2017) dalam penelitiannya menyebutkan bahwa korban yang mengalami bencana alam pasti merasakan banyak kerugian baik itu materiil dan immaterial (kehilangan pekerjaan, harta benda, kehilangan orang-orang dikasihi, mengalami kecacatan, kehilangan), akibat dari kejadian yang dialami maka korban akan merasakan dampak penderitaan psikologis yang kronis. Selain itu perasaan takut serta trauma dirasakan juga oleh empat partisipan terutama saat hujan mulai turun dimana keadaan ini membuat keluarga merasa bahwa bencana akan datang kembali ketika hujan turun tanpa henti dan membuat keluarga harus mengungsikan diri ketempat yang lebih aman. Menurut Rimayanti (2019) mengungkapkan bahwa perasaan trauma psikis terjadi ketika seseorang dihadapkan pada peristiwa yang menekan yang menyebabkan rasa tidak berdaya dan dirasakan mengancam. Berbagai macam peristiwa bencana alam dapat menimbulkan duka yang mendalam sehingga korban bencana alam akan merasa berada pada kondisi atau keadaan yang sangat tidak tenang, merasa sangat takut, serta kegelisahan yang tidak berakhir. Selain itu, para korban pun menjadi mudah mengalami panik. Serangan panik juga mempengaruhi reaksi kecemasan 
yang intens disertai dengan simtom fisik, berkeringat banyak, sesak nafas, seperti jantung berdebar-debar, dan pusing serta rasa lemas. Serangan yang terjadi disertai dengan perasaan trauma yang luar biasa dan perasaan itu akan menghantui bahwa akan segera terjadi atau bahaya akan segera menimpa sehingga adanya dorongan untuk melarikan diri dari situasi yang dialami (Nawangsih, E. 2016). Cemas juga merupakan dasar dari suatu kondisi yang dialami oleh manusia dan memberikan peringatan untuk tetap mewaspadai agar manusia bisa menghadapi stressor.Menurut Newnham (2017) dalam Yusuf, 2017) menyebutkan bahwa kesehatan mental seperti gejala stress pasca trauma, stress dan depresi bisa terjadi bagi seseorang yang terkena dampak bencana alam.

\section{Tema 4: Jenis Dukungan}

Dukungan emosional yang diberikan oleh keluarga dan warga masyarakat yang lain seperti memberikan motivasi dan menghibur masyarakat dengan cara menyanyi lagu-lagu rohani yang dapat membangunkan iman dan kepercayaan akan kehidupan selanjutnya seperti yang di ungkapkan oleh P1, P2, P3, P4 \& P5. Menurut Friedman (1998) dalam Yusuf (2017) dukungan emosional dapat memberikan perasaan nyaman, perasaan dicintai saat individu mengalami depresi, memberikan bantuan dalam bentuk empati yaitu semangat dan motivasi, dan perhatian, membuat individu akan merasa berharga serta merasa orang lain menerimanya. Selain itu dukungan emosional yang didapatkan keluarga yang terdampak bencana alam, dukungan Instrumental juga didapatkan dari berbagai sumber baik itu warga masyarakat dari luar kampung Lebo, pemerintah dan tokoh agama dukungan instrument yang diberikan yaitu segala kebutuhan hidup yang diberikan seperti pakaian, sembako, obat-obatan dan bahan material untuk membangun rumah seperti yang dingkapkan oleh P1, P2, P3, P4, P5, \& P6. Menurut Pratiwi, (2012) dalam penelitiannya mengungkapkan bahwa dukungan instrumental, merupakan bantuan yang diberikan secara langsung yang sifatnya fasilitas atau materi. Pemberian dukungan instrumental ini diberikan sangat membantu individu dalam melakukan aktivitas setiap hari sehingga mampu mengurangi perasaan ketidakmampuan untuk menjalani kehidupan. Hal ini juga diungkapkan oleh Anwaruddin (2017) dukungan instrumental yang diberikan dapat berupa bantuan sembako, sehingga dapat memperingan beban penderitaan para korban banjir.

\section{Tema 5: Beban Ekonomi}

Kerusakan yang parah bahkan kehilangan tempat tinggal sangat mempengaruhi keadaan ekonomi keluarga, dimana warga masyarakat yang terkena dampak bencana alam mengharapkan bantuan dari pemerintah untuk membangun kembali tempat tinggal yang ditelan oleh banjir saat melanda kampung Lebo. Menurut Lisnawati (2018) megungkapkan bencana alam mengakibatkan kerusakan dan kerugian. Kelangkaan barang, kerusakan infrastruktur, hilangnya sumber daya manusia merupakan beberapa faktor kerugian yang terjadi pascabencana. Bencana alam akan membebani anggaran pemerintah jika tidak dilakukan mitigasi dan pemulihan pascabencana yang tepat. Dampak kerugian secara langsung, salah satunya adalah kerugian ekonomi. Kerugian ekonomi yang secara langsung teramati adalah kerugian rusak dan hancurnya perumahan dan sektor usaha tidak hanya berakibat pada kerugian output yang tidak bisa dihasilkan, tetapi juga munculnya kemiskinan sebagai akibat dari penyesuaian kondisi struktural masyarakat yang berubah (Muttalib, 2019). Kepala keluarga memiliki tugas dan tanggung jawab dalam memenuhi keperluan setiap hari baik untuk memenuhi kebutuhan makan minum maupun kebutuhan anak sekolah akan tetapi dampak dari bencana alam ini membuat sebagaian petani kesulitan dalam mengolah hasil perkebunan karena lahan yang selama ini digunakan untuk membantu kebuhuthan setiap hari ditelan oleh banjir dan longsor pada bulan Januari 2020. Menurut Fahlia (2019) kehilangan barang berharga seperti rumah dan lahan pekerjaan dapat menyebabkan warga menjadi jatuh miskin serta tidak berdaya, terutama 
sumber mata pencaharian dan pendapatan yang tidak memungkinkan sehingga mengakibatkan sebagian warga kesulitan dalam memenuhi kebutuhan hidup.

\section{Tema 6: Makna Setelah Terjadi Bencana}

Bencana alam bisa terjadi pada siapapun dan dimanapun oleh sebab itu keluarga memaknai kejadian ini adalah kehendak dari sang pencipta untuk lebih waspada dan sebagai manusia harus ikhlas menerima kenyataan yang sudah terjadi berserah sepenuhnya kepada Tuhan sang pemilik kehidupan, seperti yang di ungkapkan oleh P1, P3, P4, P5 \& P6. Menurut Basataman (2007 dalam Sandi 2018) menerangkan bahwa makna hidup adalah suatu hal yang di anggap sangat penting dan berharga, memberikan nilai khusus bagi individu. Menurut Pangandaheng (2018) mengungkapkan dalam penelitiannya keyakinan pada Tuhan dan menerima dengan positif segala kondisinya, serta mengembalikan semuanya ke pada pemilik kehidupan. Selain itu keluarga juga mengungkapkan sudah menerima kenyataan kehilangan anggota keluarga dan harta benda karena semua yang terjadi disebabkan oleh bencana alam dan tidak bisa dihindari oleh siapapun dan berusaha pasrah dan menyerahkan semua yang dialami kepada sang pencipta seperti yang diungkapkan oleh P2, P3, P4 \& P5. Menurut Ngadiran (2010) mengatakan, menerima merupakan tahap terakhir dari tahap-tahap kehilangan. Keluarga yang bisa menerima kenyataan maka keluarga ini memiliki mekanisme koping yang baik.

\section{Tema 7: Harapan Untuk Lebo}

Setiap kejadian yang dialami oleh keluarga pastilah memiliki harapan untuk kehidupan yang akan datang terutama harapan bersama untuk kampung yang mereka tinggal saat ini. Harapan yang akan tidak lagi terjadi bencana alam, serta korban jiwa dan kehilangan barang berharga juga diungkapkan oleh P1, P2, P3, P4, P5 \& P6, semua partisipan mengungkapkan bagaimana keadaan mereka saat bencana alam itu menghampiri sehingga harapan dan doa untuk kampung Lebo adalah harapan yang positif. Menurut Sandi (2018) dalam penelitiannya mengungkapkan harapan merupakan salah satu bentuk mekanisme koping yang dilakukan individu. Melalui harapan inilah partisipan mendapatkan hasil positif yang akan muncul kembali serta membawa manfaat untuk keluarga kembali menjalani kehidupan. Harapan keluarga merupakan impian yang baik dilakukan masing-masing partisipan yang terdampak bencana alam. Harapan inilah yang dapat mendorong partisipan untuk tetap berpikir positif bahwa bencana alam tidak akan menimpa kampung Lebo lagi dan berharap bisa mendapatkan tempat tinggal yang layak untuk dihuni.

\section{KESIMPULAN}

Keadaan pasca bencana alam ini membuat keluarga yang terdampak mengalami trauma yang cukup berpengaruh dalam menjalani kehidupan seharihari. Tanda awal bencanapun dialami oleh semua partisipan dan respon yang dilakukan yaitu dengan berusaha menghindari serta melarikan diri ke tempat yang aman. Akibat dari kejadian ini menyebabkan keluarga mengalami beban psikologi karena kehilangan anggota keluarga dan harta benda serta barang berharga. Meskipun sulit menerima kenyataan harus kehilangan yang orang yang dikasihi serta benda berharga tetapi dukungan yang selalu datang dari berbagai pihak sehingga keluarga mengurangi beban yang dialami. Dengann kejadian ini keluarga mengalami perubahan ekonomi dalam memenuhi kebutuhan sehari-hari pasca bencana alam. Melalui kejadian ini keluarga memaknai bahwa ini adalah kehendak sang pencipta sehingga harapan kedepan bencana alam ini tidak akan terjadi lagi di kampung Lebo.

\section{SARAN}

Bagi masyarakat yang masih merakasakan trauma pasca bencana agar tidak panik berlebihan saat hujan turun. Tetap tenang saat mencari pertolongan 
sehingga bisa menyelamatkan anggota keluarga yang lain.

\section{DAFTAR RUJUKAN}

Anika Nova, Ah Yusuf, $\mathrm{Rr}$ Dian Tristiana.(2019).Pengalaman Adaptasi Remaja Pasca Bencana Gempa Di Lombok Nusa Tenggara Barat.https://ejournal.unair.ac.id/PNJ/article/view/13490

Anwaruddin, H. (2017). Dukungan Sosial dan Kecerdasan Emosi dengan Resiliensi Korban Banjir. Volume 6, No. 1. Jurnal Psikologi Indonesia. ISSN. 2301-5985 (Print), 2615-5168 (Online) Website: http://jurnal.untagsby.ac.id/index.php/persona

Collaizi, P. (1978). Psichological research as the phenomenologist views it. New York: Oxford University Press.

Elita Y, Sholihah A \&Sahiel S. (2017). Acceptance and Commitment Therapy (ACT) Bagi Penderita Gangguan Stress Pasca Bencana. Jurnal Konseling dan Pendidikan ISSN Cetak: 23376740 - ISSN Online: 2337-6880 DOI: https://doi.org/10.29210/117800

http://jurnal.konselingindonesia.com Volume 5 Nomor 2, 2017, Hlm 97-101

Fahlia., Irawan, E., \& Tasmin, R. (2019). Analisis Dampak Perubahan Perilaku Sosial Ekonomi Masyarakat Desa Mapin Rea Pasca Bencana Gempa Bumi. Vol. 04, No. 01 pp. 51-55. Fakultas Ekonomi dan Bisnis UTS Jurnal Ekonomi dan Bisnis Indonesia. https://media.neliti.com/media/publications/2665 00-analisis-dampak-sosial-ekonomi-pasca-ben30a35ded.pdf

Findayani, A. (2015). Kesiap Siagaan Masyarakat Dalam Penanggulangan Banjir Di Kota Semarang. Jurnal Geografi Volume 12 No 1 (103 dari 114). https://journal.unnes.ac.id/nju/index.php/JG/articl e/download/8019/5561

Lisnawati. (2018). Kerugian Ekonomi Pasca Bencana dan Upaya Menanggulanginya. Vol. X, No. 20/II/Puslit/Oktober/2018.

https://berkas.dpr.go.id/puslit/files/info_singkat/I nfo\%20Singkat-X-20-II-P3DI-Oktober-2018246.pdf
Maarif, Syamsul., Kinseng, Rilus., \& Pramono, Rudy. (2016). Jurnal Riset Bencana Indonesia. Vol. 2, No. $2 . \quad$ ISSN: 2443-2733. https://www.researchgate.net/publication/327068 855. Diakses 7 Desember 2020

Muttalib, A., (2019). Analisis Dampak Sosial Ekonomi Masyarakat Pasca Bencana Gempa Bumi Di Kabupaten Lombok Utara (KLU). Vol. 5. No. 2. Oktober 2019 p-ISSN: 2442-9511 e-ISSN: 26565862. Jurnal Ilmiah Mandala Education http://ejournal.mandalanursa.org/index.php/JIME /index

Sandi, Yudisa. D.L (2018).Pengalaman Hidup Orang Dengan Kusta Studi Fenomenologi.Tesis.http://repository.unair.ac.id/ 77610/2/TKP\%2054_18\%20San\%20p.pdf

Ngadiran, A. (2010). Studi Fenomenologi Pengalaman Keluarga Tentang Beban dan Sumber Dukungan Keluarga dalam Merawat Pasien Halusinasi. Program Magister Keperawatan Jiwa: FIK UI. http://lib.ui.ac.id/file?file=digital/137164T\%20Antonius\%20Ngadiran.pdf

Nurcahyani, F. (2016).Pengaruh Terapi Suportif Kelompok terhadap Kecemasan pada Klien Pasca Bencana Banjir Bandang di Perumahan Relokasi Desa Suci Kecamatan Panti Kabupaten Jember.e-Jurnal Pustaka Kesehatan, vol.4 (no.2), Mei, 2016. https://jurnal.unej.ac.id/index.php/JPK/article/vie $\mathrm{w} / 3205$.

Nawangsih, E. (2016). Play Therapy Untuk anak-anak Korban Bencana Alam Yang Mengalami Trauma (Post Traumatic Stress Disorder/PTSD). Jurnal Ilmiah Psikologi Juni 2014, Vol. 1, No.2.Psympathic, 1(2), 164178.https://www.researchgate.net/publication/32 2792284_

Pangandaheng N.D. (2018). Pengalaman Keluarga Merawat Klien dengan Gangguan Jiwa di Kabupaten Kepulauan Sagihe. R-Perpustakaan Universitas Airlangga. TESIS. http://repository.unair.ac.id/78133/2/TKP\%2075 _18\%20Pan\%20p.pdf

Pratiwi, I.H \& Laksmiwati, H. (2012).Pengaruh dukungan Emosional, dukungan penghargaan, dukungan Instrumental dan dukungan Informatif terhadap Stres Pada remaja di Yayasan Panti Asuhan Putra Harapan Asrori Malang.Journal. Unesa.ac.id.https://jurnalmahasiswa.unesa.ac.id/i ndex.php/character/article/view/1925 
Purwastuty, I. (2019). Kecemasan Masyarakat Terhadap Bencana Banjir Bandang di Desa Batuganda Kecamatan Lasusua Kabupaten Kolaka Utara. Jurnal Mimbar Kesejahteraan Sosial, Edisi 2 Mei 2019 ISSN: (p) 2655-0911 (e) $2655-7320$

Rimayati, E. (2019). Pendekatan dalam Mereduksi Trauma Masyarakat Pasca Bencana Tsunami di Selat Sunda. p-ISSN 2252-6374. Indonesian Journal of Guidance and Counseling: Theory and Application

http://journal.unnes.ac.id/sju/index.php/jbk

Ridha, R. \& Husna, C. (2017). Pengetahuan dan Sikap Masyarakat Terhadap Tindakan Penanggulangan Banjir. Jurnal Ilmiah Mahasiswa Vol 2, No 4.
http://jim.unsyiah.ac.id/FKep/article/view/3863

Santiago, P.N., Ursano, R.J., Gray, C.L., Pynoos, R.S., Spiegel, D., Lewis-Fernandez,R., Fredman, M.J., dan Fullerton, C.S. (2013), A systematic review of PTSD prevalence and trajectories in DSM-5 defned trauma ecxposed population, Plos One, April 2013, Volume 8, Issue 4

Tondobala L.(2011). Pendekatan Untuk Menentukan Kawasan Rawan Bencana Di Pulau Sulawesi. Jurnal Sabua Vol.3, No.3: 40-52, Agustus 2011 ISSN 2085-7020. http://ejournal.unsrat.ac.id

Yusuf,.A. (2017)Fenomena Pasung dan Dukungan Keluarga terhadap Pasien Gangguan Jiwa Pasca Pasung. (online), Volume 5 Nomor 3. http:// jkp.fkep.unpad.ac.id. Jurnal Keperawatan. 